\title{
An international survey of polypectomy training and assessment
}

\section{(웅 $\circledast$}

\section{Authors}

K. Patel ${ }^{1,2}$, A. Rajendran ${ }^{1,3}$, O. Faiz',, M. D. Rutter ${ }^{4,5}$, C. Rutter ${ }^{6}$, R. Jover ${ }^{7}$, I. Koutroubakis ${ }^{8}$, W. Januszewicz ${ }^{9,10}$, M. Ferlitsch ${ }^{11}$, E. Dekker ${ }^{12}$, D. Maclntosh ${ }^{13}$, S. C. $\mathrm{Ng}^{14}$, T. Kitiyakara ${ }^{15}$, H. Pohl ${ }^{16}$, S. Thomas-Gibson ${ }^{1,2}$

Institutions

1 Wolfson Unit for Endoscopy, St Mark's Hospital, London, UK

2 Imperial College, London, UK

3 King's College London, London, UK

4 North Tees \& Hartlepool NHS Foundation Trust, Stockton-onTees, UK

5 Durham University, Durham, Co. Durham, UK

6 British Society of Gastroenterology, UK

7 Hospital General Universitario de Alicante, Alicante, Spain

8 University Hospital Heraklion, Crete, Greece

9 The Maria Sklodowska-Curie Memorial Cancer Center and Institute of Oncology, Warsaw, Poland

10 Department of Gastroenterology and Hepatology, Medical Center for Postgraduate Education, Warsaw, Poland

11 Medical University of Vienna, Vienna, Austria

12 Academic Medical Center, Amsterdam, Netherlands

13 Dalhousie University, Halifax, Nova Scotia, Canada

14 Department of Medicine and Therapeutics, Chinese University of Hong Kong, Hong Kong, China

15 Ramathibodi Hospital, Mahidol University, Bangkok, Thailand

16 Geisel School of Medicine, Dartmouth, Hanover, NH, USA

submitted 15.6.2016

accepted after revision 4.10 .2016

\section{Bibliography}

DOI http://dx.doi.org/10.1055/s-0042-119949 |

Endoscopy International Open 2017; 05: E190-E197

(c) Georg Thieme Verlag KG Stuttgart · New York

ISSN 2364-3722
Corresponding author

Kinesh Patel, St Mark's Hospital - Wolfson Unit for Endoscopy,

Watford Road, London HA1 3UJ, UK

Fax: +44-20-30041010

kinesh.patel@gmail.com

\section{ABSTRACT}

Background and study aims Colonic polypectomy is acknowledged to be a technically challenging part of colonoscopy. Training in polypectomy is recognized to be often inconsistent. This study aimed to ascertain worldwide practice in polypectomy training.

Patients and methods An electronic survey was distributed to endoscopic trainees and trainers in 19 countries asking about their experiences of receiving and delivering training. Participants were also asked about whether formal polypectomy training guidance existed in their country.

Results Data were obtained from 610 colonoscopists. Of these responses, 348 (57.0\%) were from trainers and $262(43.0 \%)$ from trainees; $6.6 \%$ of trainers assessed competency once per year or less often. Just over half (53.1\%) of trainees had ever had their polypectomy technique formally assessed by any trainer. Approximately half the trainees surveyed $(51.1 \%)$ stated that the principles of polypectomy had only ever been taught to them intermittently. Of those trainees with the most colonoscopy experience, who had performed over 500 procedures, $48.2 \%$ had had training on removing large polyps of over $10 \mathrm{~mm} ; 46.2 \%$ (121 respondents) of trainees surveyed held no record of the polypectomies they had performed. Only four of the 19 countries surveyed had specific guidelines on polypectomy training.

Conclusions A significant number of competent colonoscopists have never been taught how to perform polypectomy. Training guidelines worldwide generally give little direction as to how trainees should acquire polypectomy skills. The learning curve for polypectomy needs to be defined to provide reliable guidance on how to train colonoscopists in this skill.

\section{Introduction}

The use of colonoscopy for diagnostic purposes in symptomatic patients and colorectal cancer screening is increasing worldwide. Variability in colonoscopist performance is well-documented [1, 2]. In an effort to ensure that practitioners are competent before working independently, many countries have been trying to move to competency-based assessments of the colonoscopy technique from requiring purely numerical documentation of completed procedures.

Arguably the most challenging part of colonoscopy is polypectomy, accounting for the majority of serious complications: post-colonoscopy bleeding and perforation [3,4]. Training in polypectomy has been variable with some trainees receiving little in the way of formal guidance before being expected to perform colonoscopy with polypectomy independently. In addition, until recently there has been no validated structured way to assess competency at polypectomy [5]. Data on the learning curve for polypectomy are limited. One prospective study suggested that 250 polypectomy procedures are needed before trainees achieve a competency level similar to that of experienced colonoscopists [6].

The Directly Observed Polypectomy Skills (DOPyS) tool has been devised to permit documentation of polypectomy compe- 
tency [5]. In the UK, polypectomy assessment has now been deemed mandatory as part of the colonoscopy certification process, with trainees having to demonstrate competency in the removal of polyps up to $1 \mathrm{~cm}$ for provisional certification, as well as meeting key performance indicators including cecal intubation rate, sedation practice, and polyp detection rate to obtain provisional certification.

Full certification for colonoscopy and polypectomy is subsequently awarded with evidence of at least four satisfactory DOPyS, with a minimum of two assessments tackling both sessile and pedunculated lesions and a period of independent practice of a further 100 colonoscopies.

The American Society for Gastrointestinal Endoscopy (ASGE) has developed a competency framework for colonoscopy, including both cognitive and motor skills, to improve training and assessment of colonoscopy including polypectomy [7]. This assessment of competency in endoscopy (ACE) tool is similar to the colonoscopy DOPyS utilized in the UK.

It is unclear whether other countries have highlighted polypectomy as a specific skill that needs to be taught. There are also no data on how training and assessment of polypectomy are currently delivered around the world.

\section{Aims}

The principal aims of the study were to assess both trainees' and trainers' experience of polypectomy training in countries around the world and to ascertain which guidelines exist for polypectomy competency assessment.

\section{Materials and methods Participants}

International leaders in the field of colonoscopy, many of whom belong to the World Endoscopy Organization (WEO), were initially asked if they were willing to take part in an international survey. If there was no representative identified from the WEO, or the endoscopist declined to participate, an email was sent to an endoscopist known to be interested in training asking if they wished to participate in the survey.

Local representatives in each country were asked to provide email access to a national database of trainees or, where this was not available, a regional list of endoscopy trainees comprising where possible those with both a medical and surgical background. A further list of endoscopy trainers was also requested.

\section{Guidelines}

Each representative was asked to forward guidelines from their respective countries relating to polypectomy training and competency assessment. If no guidelines existed, members were asked to confirm this.

\section{Survey}

An online survey was created asking separate questions to trainees and trainers. The survey was administered in English and emailed to all participants in 2014. No further guidance on completing the questionnaire was given. The information
- Table 1 Information collected from endoscopists.

\begin{tabular}{|l|l|}
\hline Trainee & Trainer \\
\hline Specialty & Specialty \\
\hline $\begin{array}{l}\text { Awareness of national guidelines } \\
\text { in polypectomy }\end{array}$ & $\begin{array}{l}\text { Awareness of national guidelines } \\
\text { in polypectomy }\end{array}$ \\
\hline Colonoscopy experience & Use of guidelines when training \\
\hline Formal polypectomy teaching & Frequency of delivering training \\
\hline Polypectomy experience & $\begin{array}{l}\text { History of polypectomy assess- } \\
\text { ment training }\end{array}$ \\
\hline
\end{tabular}

sought is shown in Table 1 . Completion of all applicable questions was mandatory to successfully submit the survey.

\section{Results}

\section{Participants}

Data were obtained from 610 colonoscopists. Of these responses, 348 (57.0\%) were from trainers and 262 (43.0\%) from trainees. In total, 19 countries or territories were represented in the survey spanning five continents ( $\triangleright$ Table 2 , $\triangleright$ Fig.1).

\section{Trainers}

Trainers originated from all 19 countries participating in the survey ( $>$ Fig.2). Responses where the country of origin was outside the surveyed countries have been classified as 'Other'. The largest contribution to this part of the survey came from Spain, with 86 responses recorded.

The majority $(92.2 \%, 321 / 348$ respondents, $95 \% \mathrm{Cl} 89.4-$ $95.1 \%)$ of trainers had their origins in medical gastroenterology, with $6.6 \%$ (23/348 respondents, $95 \% \mathrm{Cl} 4.0-9.2 \%)$ having a background in surgery.

\section{Trainees}

Trainees from 17 countries responded to the survey ( $>$ Fig. 3 ). The two countries from which no trainee responses were obtained were Germany and Nigeria.

Again, the majority $(90.5 \%, 237 / 262$ respondents, $95 \% \mathrm{Cl}$ $86.9-94.0 \%$ ) of trainees had a primary specialty of medical gastroenterology, with a small proportion (3.8\%, 10/262 respondents, $95 \% \mathrm{Cl} 1.5-6.1 \%)$ training in surgery.

\begin{tabular}{|l|l|l|}
\hline \begin{tabular}{l|l} 
Table 2 \\
Australia
\end{tabular} & Countries or territories participating in the study. \\
\hline Austria & Hong Kong & Spain \\
\hline Canada & Japan & Thailand \\
\hline France & New Zealand & Italy \\
\hline Germany & Nigeria & UK \\
\hline Greece & Sudan & USA \\
\hline Holland & Poland & \\
\hline
\end{tabular}




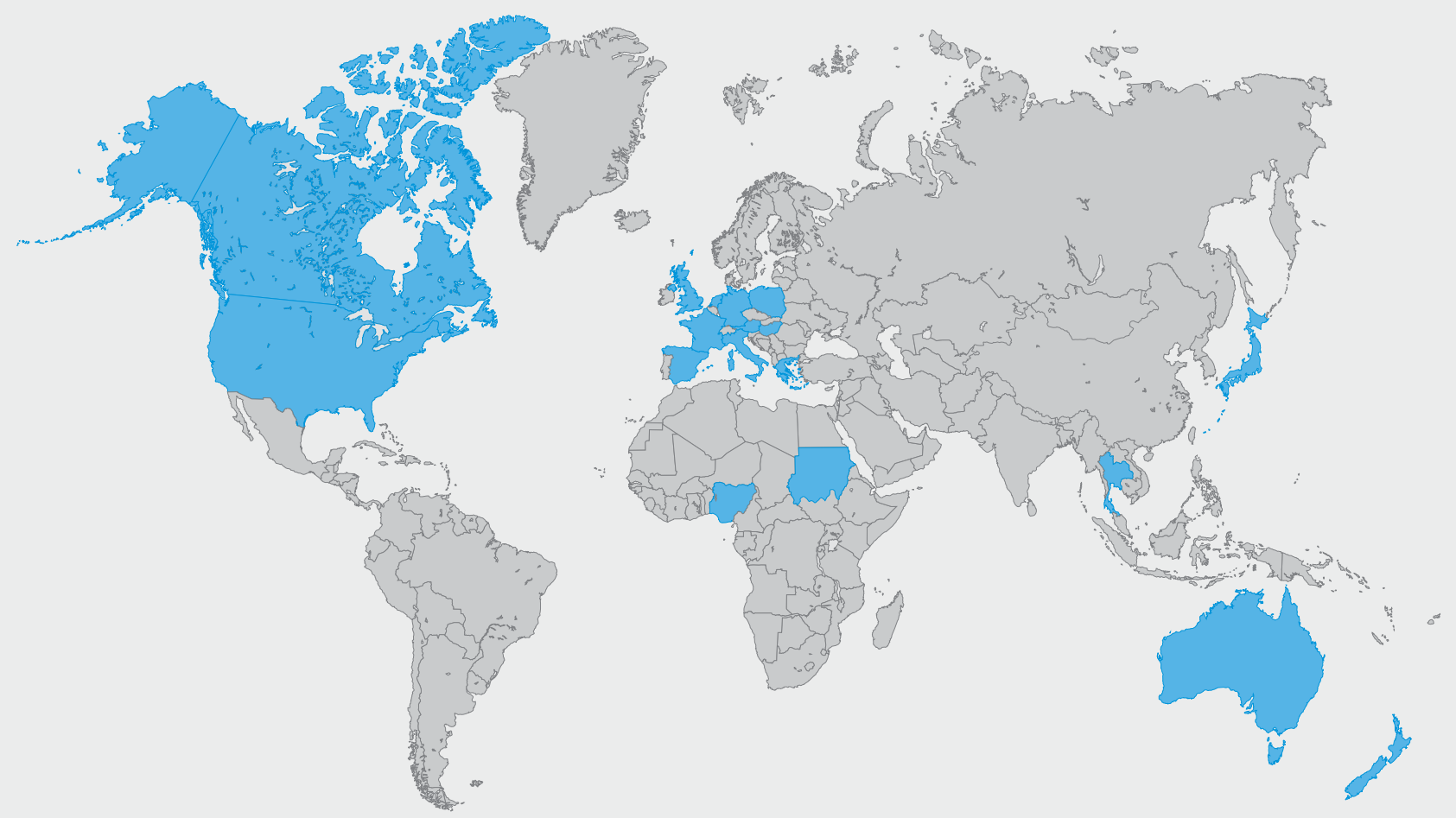

- Fig. 1 Countries or territories participating in the study.

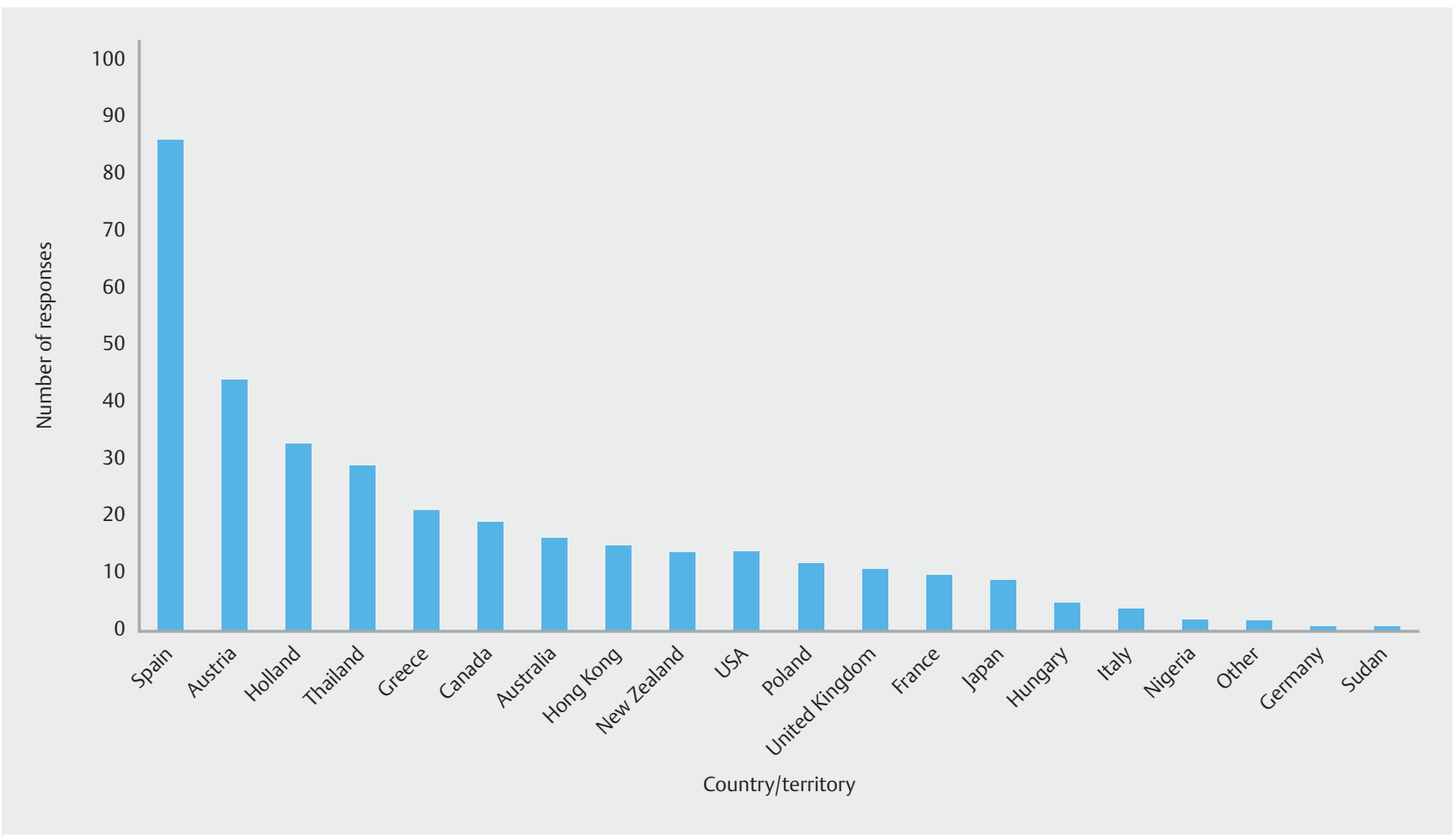

- Fig. 2 Trainer responses by country. 


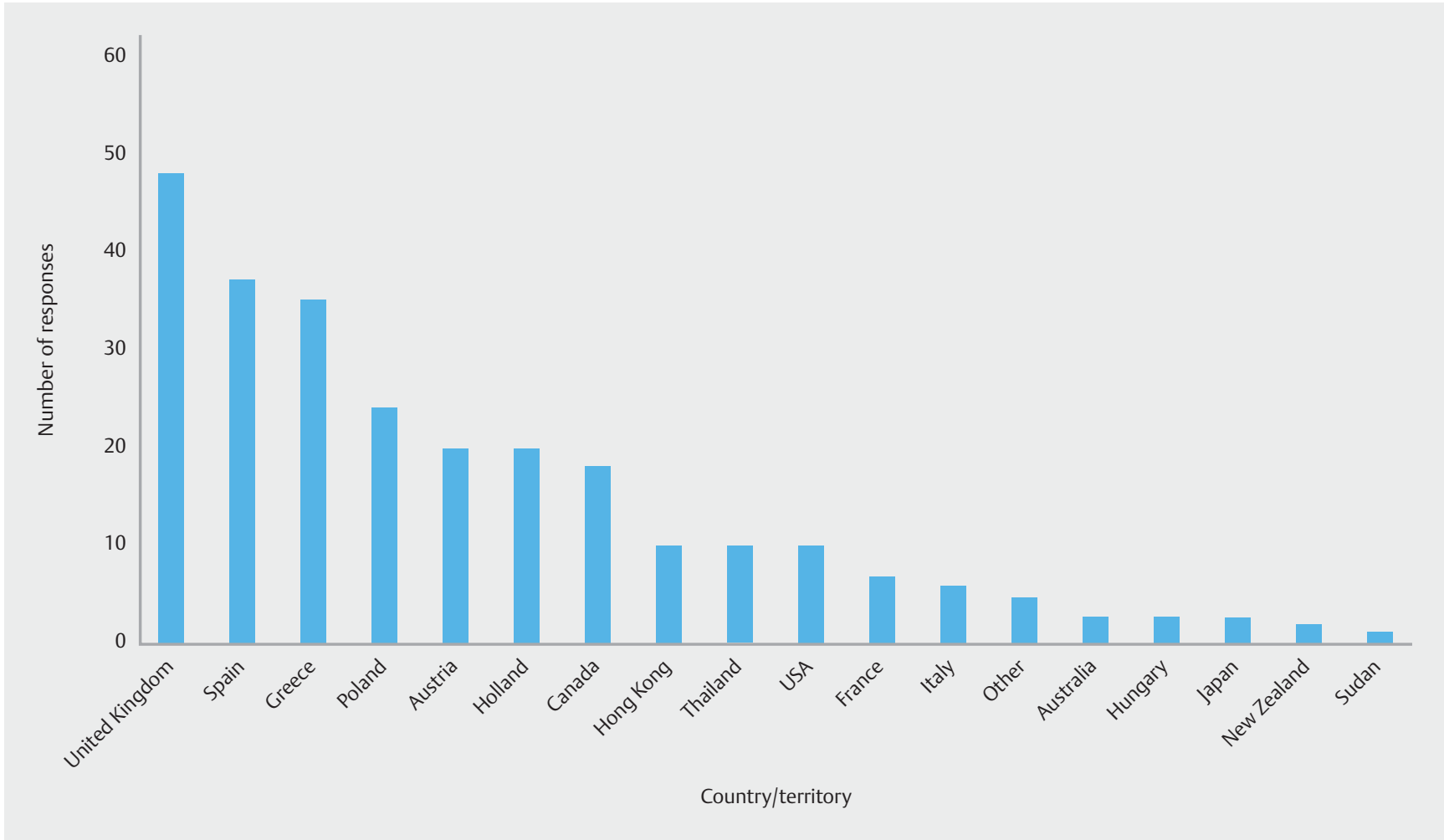

- Fig. 3 Trainee responses by country.

\section{Trainer survey}

The majority (79.6\%, 277 respondents, $95 \% \mathrm{Cl} 75.4-83.8 \%$ ) of the 348 trainers surveyed were involved in trainee polypectomy assessment weekly (> Fig. 4). Twelve respondents (3.4\%, $95 \%$ $\mathrm{Cl} 1.5-5.4 \%$ ) considered themselves polypectomy trainers but never formally assessed their trainees' competency at polypectomy and 11 trainers $(3.2 \%, 95 \% \mathrm{Cl} 1.3-5.0 \%)$ stated that they only performed assessments annually.

\section{Awareness and utilization of guidelines}

A small majority of trainers (58.9\%, 205/348 respondents, $95 \%$ $\mathrm{Cl} 53.7-64.1 \%$ ) were aware of the existence of guidelines about training in polypectomy. Of this group, 180 stated that they used polypectomy guidelines when training endoscopists, with $25(12.2 \%$, $95 \% \mathrm{Cl} 7.7-16.7 \%)$ not using any guidelines.

Multiple responses were received from trainers when asked to state the guidelines that they used. The most commonly cited guidelines, mentioned by 50 respondents were the ASGE guidelines. Significant numbers also said that they used BSG, AGA, and European guidelines ( $>$ Table 3 ). Participants were not asked to select from a list of known guidelines as the question was designed to test what training guidelines trainers perceived existed. For example, the AGA or ESGE do not have a specific guideline on polypectomy training.

Just over half $(51.1 \%, 178 / 348$ respondents, $95 \% \mathrm{Cl} 45.9-$ $56.4 \%$ ) of the trainers surveyed said that they used a framework when assessing polypectomy. Most of these individuals (130 respondents) were those who used polypectomy guidelines to train other endoscopists.

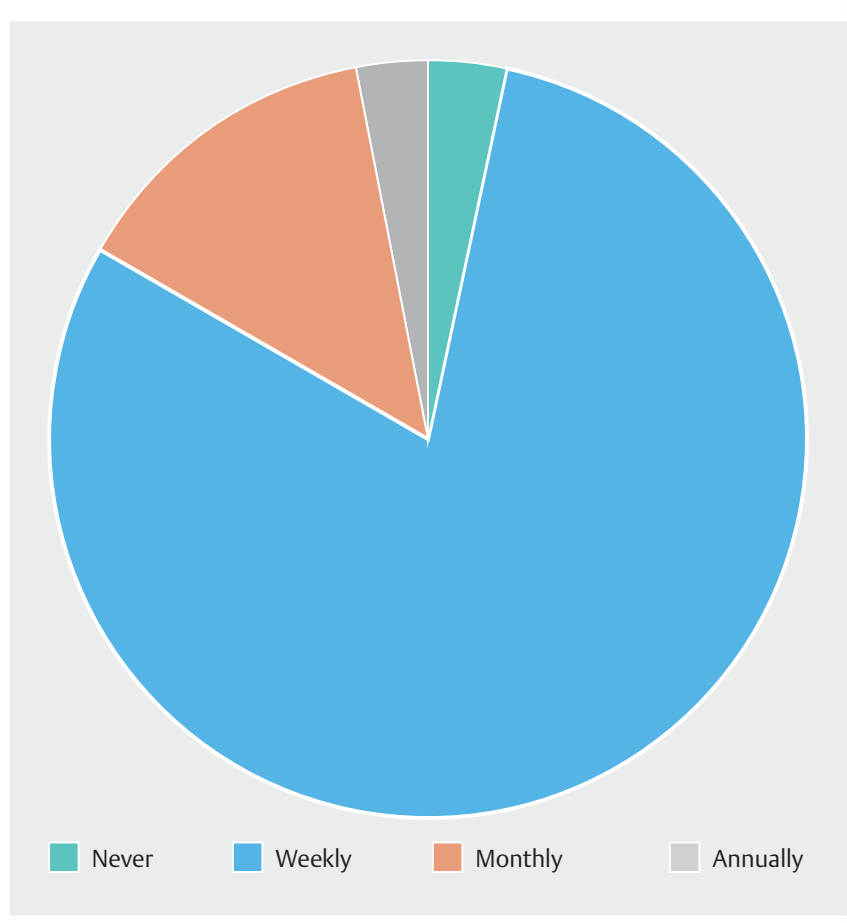

Fig. 4 Frequency of polypectomy competency assessments by trainers. 
- Table 3 Guidelines quoted by trainers to assess polypectomy.

\begin{tabular}{|l|c|}
\hline Guideline & Number of responses \\
\hline ASGE & 50 \\
\hline European/ESGE & 33 \\
\hline AGA & 19 \\
\hline BSG & 16 \\
\hline DOPyS & 7 \\
\hline In house/local & 13 \\
\hline
\end{tabular}

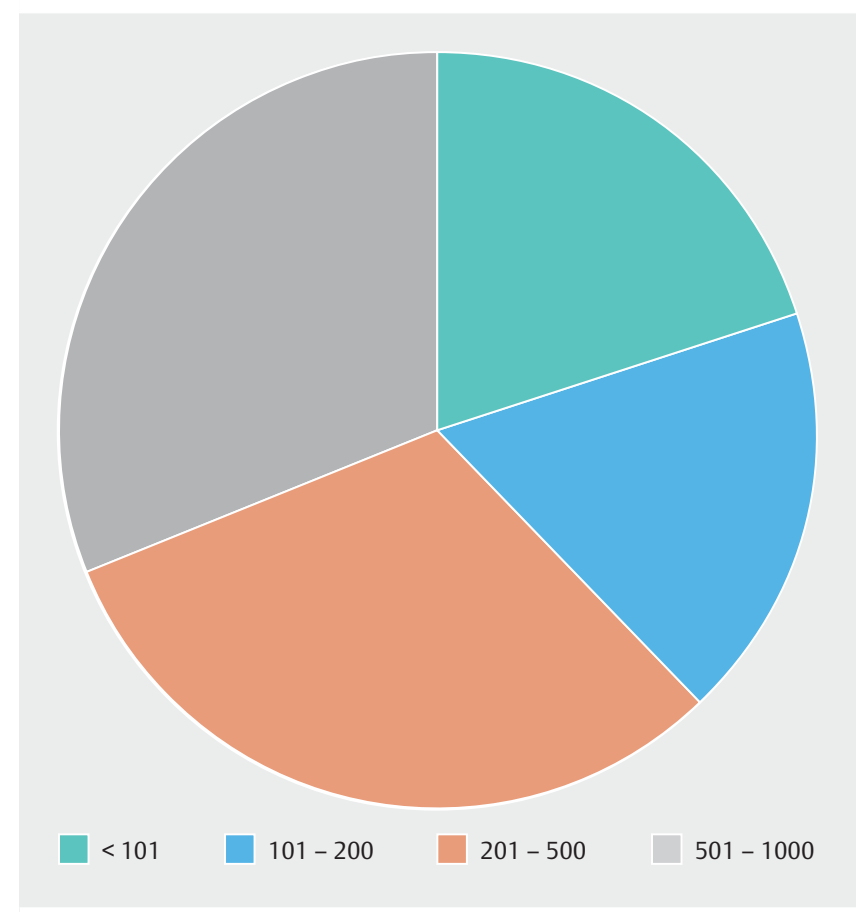

Fig. 5 Number of colonoscopies performed by trainees.

\section{Trainee survey}

Most trainees (76.7\%, 201/262 respondents, 95\%Cl $71.6-$ $81.8 \%$ ) commenced endoscopic training within the years 2008-2012 and qualified from medical school after the year 2000 (80.9\%, 212/262 respondents, $95 \% \mathrm{Cl} 76.2-85.7 \%)$. The survey included those with a breadth of colonoscopic experience ( $\mathbf{F i g . 5}$ ) with $31.7 \%(83 / 262$ respondents, $95 \% \mathrm{Cl} 26.0$ $37.3 \%)$ having completed more than 500 colonoscopies and $38.2 \%$ (100/262 respondents, $95 \% \mathrm{Cl} 32.3-44.1 \%)$ having completed fewer than 200 procedures.

\section{Polypectomy experience}

Trainees were asked whether they had been formally taught the principles behind polypectomy. A minority had never received such teaching, with approximately half $(51.1 \%, 134 / 262$ respondents, $95 \% \mathrm{Cl} 45.1-57.2 \%$ ) stating that these principles had only been taught intermittently. A significant minority (8.4\%, $22 / 262$ respondents, $95 \% \mathrm{Cl} 5.0-11.8 \%$ ) of those who

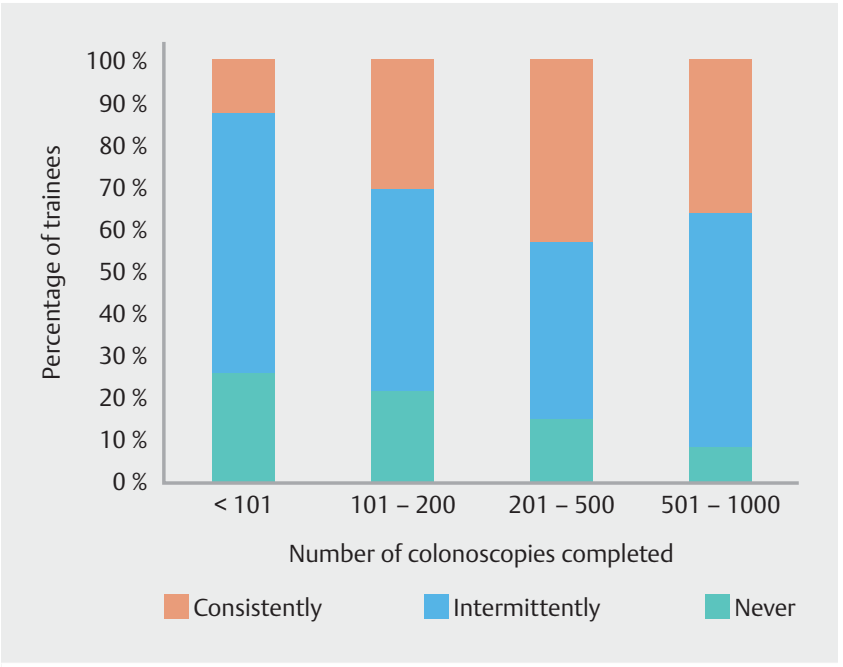

Fig. 6 Number of colonoscopies performed by trainees and proportion taught the principles of polypectomy.

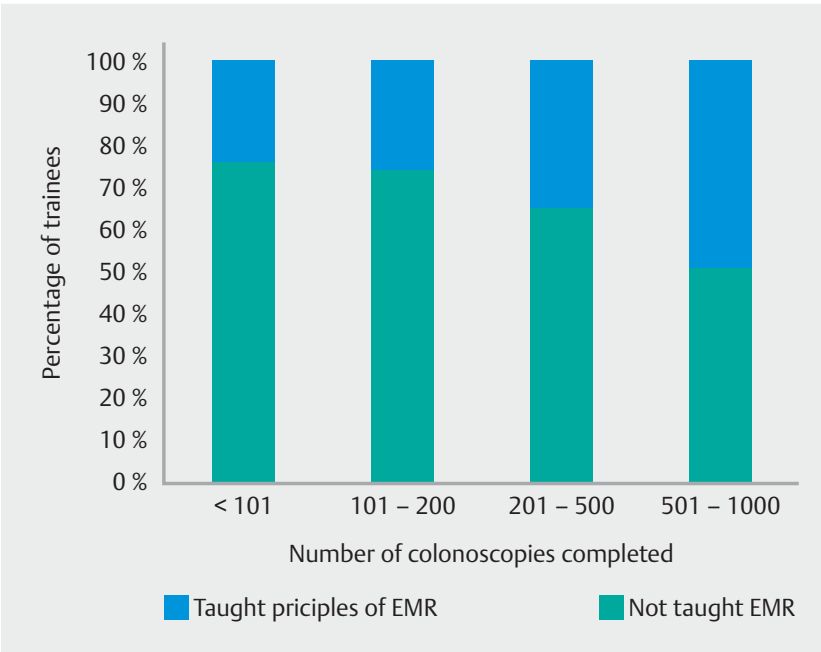

Fig. 7 Number of colonoscopies performed by trainees and proportion taught the principles of endoscopic mucosal resection (EMR).

had performed the most colonoscopies had never been taught about polypectomy ( $\triangleright$ Fig. $\mathbf{6})$.

Most (64.1\%, 168/262 respondents, $95 \% \mathrm{Cl} 58.3-69.9 \%$ ) trainees had never been taught the principles of endoscopic mucosal resection (EMR). Of those with the most experience, having performed more than 500 colonoscopies, 49.4\% (41/83 respondents, $95 \% \mathrm{Cl} 38.6-60.2 \%$ ) had received teaching on the theory behind EMR ( $\triangleright$ Fig. 7).

\section{Use of guidelines}

A minority of trainees used guidelines to direct their polypectomy training. In total, $32.8 \%$ (86/262 respondents, $95 \% \mathrm{Cl} 27.1$ $38.5 \%$ ) used national guidelines but a larger proportion, $43.1 \%$ (113/262 respondents, $95 \% \mathrm{Cl} 37.1-49.1 \%$ ), were aware of the existence of guidelines but chose not to use them. Seventeen 
trainees quoted American guidelines, encompassing the AGA and ASGE, and all 22 trainees from the UK stated they used guidelines when training utilizing JAG guidance. No trainees from outside the UK mentioned JAG or DOPyS, instead usually referring to their own national or continental guidelines.

\section{Hands-on training}

Just over half $(53.1 \%, 139 / 262$ respondents, $95 \% \mathrm{Cl} 47.0-$ $59.1 \%$ ) of trainees had ever had their polypectomy technique formally assessed by any trainer. Of the 262 trainees, $67.6 \%$ (177 respondents, $95 \% \mathrm{Cl} 61.9-73.2 \%$ ) stated that they were competent at polypectomy. Of this self-certified competent group, 70 colonoscopists had never had a formal evaluation of their polypectomy technique.

\section{Documentation}

When asked how polypectomies that had been formally assessed were documented, $52.3 \%$ of trainees (68/130 respondents, $95 \% \mathrm{Cl} 43.7-60.9 \%$ ) used either a formal polypectomy assessment form or other generic form. However, $49.2 \%$ (64/130 respondents, $95 \% \mathrm{Cl} 40.6-57.8 \%$ ) stated that the polypectomy assessment process was not documented in any form.

Trainees were also asked about whether they kept a record of polypectomies performed in a logbook; 46.2\% (121/262 respondents, $95 \% \mathrm{Cl} 40.1-52.2 \%)$ of trainees held no record of the polypectomies they had performed; however, $43.1 \%$ (113/ 262 respondents, $95 \% \mathrm{Cl} 37.1-49.1 \%$ ) of trainees did so regularly.

\section{Large polyps}

Most trainees had not received training for larger polyps, those over $10 \mathrm{~mm}$. Overall, only $32.8 \%$ (86/262 respondents, $95 \% \mathrm{Cl}$ $27.1-38.5 \%$ ) said that they had been taught specific skills to deal with these larger lesions. Of those with the most colonoscopy experience, who had performed over 500 procedures, $48.2 \%$ (40/83 respondents, $95 \% \mathrm{Cl} 37.4-58.9 \%$ ) had had large polypectomy instruction ( $\mathbf{F i g . 8}$ ).

Trainees who deemed themselves competent had had similar levels of training for larger polyps with $42.9 \%$ (76/177 respondents, $95 \% \mathrm{Cl} 35.6-50.2 \%$ ) having been trained specifically in this way.

\section{Guidelines review}

Responses were received from each of the local representatives outlining polypectomy training in their own country ( $\triangleright \mathrm{Ta}$ ble 4). Only a minority of countries had specific guidelines devoted to polypectomy.

\section{Discussion}

Fifteen of the 19 countries surveyed had no specific guidance on how polypectomy competency should be documented or how trainers should undertake assessing trainees. Even in countries where such guidance does exist, such as the UK, a significant proportion of trainees were unaware of such guidance or did not use it in their training. Both of these issues need addressing.

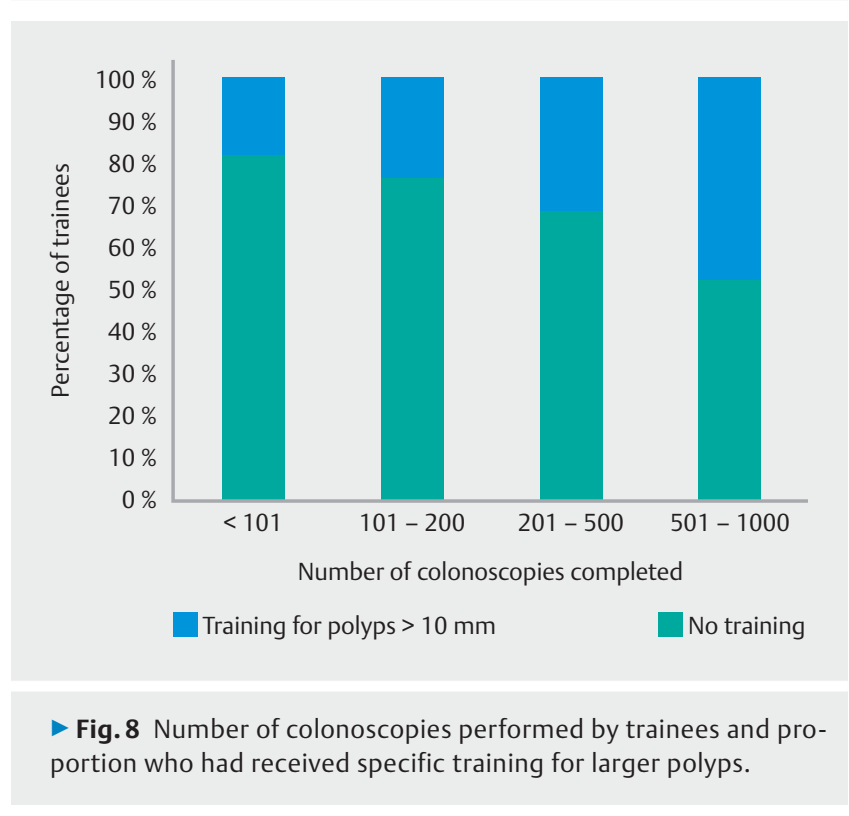

There have been significant recent advances in endoscopic knowledge and techniques and it seems prudent that trainees benefit from this to improve patient outcomes. As a result of the increased risk of perforation [8], the demise of hot biopsy as a method for removing diminutive polyps is a good example of the importance of ensuring trainees are instilled with both the appropriate technical and judgment skills necessary to perform polypectomy safely. In an era where the utilization of polypectomy as a tool to prevent colorectal cancer in often healthy individuals is increasing inexorably, the gaps in training identified by the survey are concerning.

Only a small majority of trainers in the survey were aware of national guidelines with regard to polypectomy assessment. The analysis of these guidelines demonstrated little reference to the mechanics of polypectomy assessment and training, instead largely referring to documents detailing surveillance intervals for patients with polyps. It is likely that most trainers internationally did not have access to validated formal guidance on polypectomy assessment.

In addition, most trainers did not have a structured way in which to assess polypectomy, which makes the reproducibility of both teaching and the assessment of competency of trainees challenging, especially when several trainers have differing approaches.

Only a minority of trainers had received training themselves on how to assess competency at polypectomy. Previous work has shown that there is significant variability in both polypectomy technique and assessment of competence [5]. With complex, multi-step tasks such as polypectomy, a standardized approach across trainers and different centers is likely to benefit trainees and improve the rate of skills acquisition.

Almost $80 \%$ of trainers described themselves as performing weekly polypectomy assessments, yet only $53.1 \%$ of trainees stated that their polypectomy technique had been assessed formally. This discrepancy may be due to a mismatch in the 
- Table4 Polypectomy training requirements in countries surveyed.

\begin{tabular}{|l|l|}
\hline Country & Polypectomy guidance \\
\hline Australia & Minimum number of 30 snare polypectomies needed \\
\hline Austria & No polypectomy guidance \\
\hline Canada & Minimum number of 30 snare polypectomies needed \\
\hline France & No polypectomy guidance \\
\hline Germany & No polypectomy guidance \\
\hline Greece & No polypectomy guidance \\
\hline Holland & No polypectomy guidance \\
\hline Hong Kong & No polypectomy guidance \\
\hline Hungary & No polypectomy guidance \\
\hline Japan & No polypectomy guidance \\
\hline New Zealand & No polypectomy guidance \\
\hline Nigeria & No polypectomy guidance \\
\hline Sudan & No polypectomy guidance \\
\hline Poland & No polypectomy guidance \\
\hline Spain & No polypectomy guidance \\
\hline Thailand & No polypectomy guidance \\
\hline Italy & No polypectomy guidance \\
\hline UK & $\begin{array}{l}\text { Ja guidance }- \text { numbers and technique via assess- } \\
\text { USA }\end{array}$ \\
\hline
\end{tabular}

centers where trainers and trainees responding to the survey were located.

It is disappointing that, internationally, a significant number of trainees were aware of the existence of national guidelines specifically relating to polypectomy but did not use them in their own training. There are likely to be myriad reasons for this including individual motivation, perceived lack of relevancy, and the attitude of trainers.

The lack of specific training in EMR and larger polypectomy is also a concern. Many trainees in the survey had completed what would be regarded as very significant numbers of colonoscopies, yet had never been taught or assessed on polypectomy. The concern is that some endoscopists may be deemed competent at therapeutic colonoscopy including polypectomy after attaining high performance metrics at diagnostic colonoscopy only. These colonoscopists may be exposing patients undergoing polypectomy to an excess risk. The British Society of Gastroenterology has recently published guidelines with a suggested training path for endoscopists wishing to undertake EMR of larger lesions [9].

In the UK, the differences between training in colonoscopy and polypectomy are addressed by having a two tier certification system whereby trainees are first judged competent at diagnostic colonoscopy and sub-centimeter polypectomy, and only then can progress to performing supervised polypectomy on larger lesions with full certification thereafter.
The vast majority of publications relating to competency in colonoscopy relate to the skills required to attain the technical ability to reach the cecum reliably $[10-14]$. It is only recently that a consensus has developed on the number of colonoscopies that trainees need to perform to be able to pass the endoscope safely to the cecum [15].

The reasons for this focus are likely to be twofold. First, in the past, diagnostic colonoscopy skills were often poor with significant numbers of patients undergoing incomplete colonoscopy [16]. Diagnostic standards have risen in many countries but it seems that training in therapeutic colonoscopy needs to undergo a similar transformation.

Secondly, measurement of the cecal intubation rate is a simple binary outcome for each patient. As such, this lends itself to easy measurement and analysis. In contrast, polypectomy is only performed in a minority of patients and the skills involved differ significantly between patients due to the inherent complexities of the technique.

In addition, whereas the cecal intubation rate is widely accepted as a quality mark for colonoscopy, no such consensus exists for the quality of polypectomy. The DOPyS has endeavored to bridge this gap and has gained some international acceptance but this is by no means universal. It is clear however that competency in diagnostic colonoscopy does not confer similar competency in therapeutics [5]. The introduction of DOPyS into English Bowel Cancer Screening accreditation was in direct response to the initial process testing diagnostic colonoscopy skills to a high standard but neglecting the key mandatory therapeutic aspects of the procedure.

Some international guidelines specify a minimum number of snare polypectomies but it is increasingly appreciated that assessment based on procedural volume is outdated and instead, assessment should be focused on competency-based training identifying the achievement of milestones.

This is the broadest geographical survey to have ever been conducted, specifically assessing the international experience of polypectomy from countries around the world. The inclusion of both trainees and trainers from geographically disparate areas is a strength.

However, the method of recruitment of those to be included, partly through the expert forum of the WEO and partly through personal contacts interested in training in endoscopy, is likely to have resulted in significant selection bias with endoscopists at higher volume, academic centers more likely to have been represented. These endoscopists were more likely to formally assess polypectomy of trainees and also be aware of and use guidelines. This bias is most likely to have been reflected by these results showing the best case scenario: it is likely that the overall training landscape in the countries surveyed is poorer than that represented in this study.

In addition, the majority of responses came from Europe and North America with a minority from Africa, Asia, and Australasia, which may diminish the representativeness of the survey. Due to the recruitment strategy, some individual countries were over-represented in the results and this is likely to have skewed the data to some extent. In many cases, particularly but not exclusively in the developing world, it was not possible 
to survey the entire nation's endoscopic trainees as many countries do not keep reliable central databases of those undergoing endoscopic training.

This study assessed polypectomy at large. Further knowledge gaps and variations in teaching and assessment are likely for more complex techniques such as cold snare polypectomy and saline cushion-assisted polypectomy. Another limitation is that the degree of supervision for colonoscopy was not assessed; it is likely that some of the trainees may have been performing colonoscopy and polypectomy without direct in room supervision by a trainer.

In conclusion, there is a need for an international consensus as to what constitutes a competent polypectomy. In addition, the learning curve for this procedure and its variants needs to be defined to provide guidance to those learning therapeutic colonoscopy so the many successes of colonoscopy in preventing colorectal cancer are not marred by iatrogenic complications. Those delivering training need to be trained themselves to ensure standardization in the methods they use to teach and assess trainees in this complex skill.

\section{Competing interests}

None

\section{References}

[1] Cotton PB, Connor P, McGee D et al. Colonoscopy: practice variation among 69 hospital-based endoscopists. Gastrointest Endosc 2003; 57: $352-357$

[2] Minoli G, Meucci G, Prada A et al. Quality assurance and colonoscopy. Endoscopy 1999; 31: $522-527$

[3] Heldwein W, Dollhopf M, Rosch T et al. The Munich Polypectomy Study (MUPS): prospective analysis of complications and risk factors in 4000 colonic snare polypectomies. Endoscopy 2005; 37: 1116 1122
[4] Rutter MD, Nickerson C, Rees C] et al. Risk factors for adverse events related to polypectomy in the English Bowel Cancer Screening Programme. Endoscopy 2014; 46: 90 - 97

[5] Gupta S, Anderson J, Bhandari P et al. Development and validation of a novel method for assessing competency in polypectomy: direct observation of polypectomy skills. Gastrointest Endosc 2011; 73: 1232 1239.e2

[6] Boo S-J, Jung JH, Park JH et al. An adequate level of training for technically competent colonoscopic polypectomy. Scand J Gastroenterol 2015; 50: 908 - 915

[7] Sedlack RE, Coyle W], Obstein KL et al. ASGE's assessment of competency in endoscopy evaluation tools for colonoscopy and EGD. Gastrointest Endosc 2014; 79: 1

[8] Anderloni A, Jovani M, Hassan C et al. Advances, problems, and complications of polypectomy. Clin Exp Gastroenterol 2014; 7: 285-296

[9] Rutter MD, Chattree A, Barbour JA et al. British Society of Gastroenterology/Association of Coloproctologists of Great Britain and Ireland guidelines for the management of large non-pedunculated colorectal polyps. Gut 2015; 64: $1847-1873$

[10] Sedlack RE. Training to competency in colonoscopy: assessing and defining competency standards. Gastrointest Endosc 2011; 74: $355-$ 366.e1-2

[11] Spier B], Benson M, Pfau PR et al. Colonoscopy training in gastroenterology fellowships: determining competence. Gastrointest Endosc 2010; 71: 319-324

[12] Spier B], Durkin ET, Walker AJ et al. Surgical resident's training in colonoscopy: numbers, competency, and perceptions. Surg Endosc 2010; $24: 2556-2561$

[13] Church J, Oakley J, Milsom J et al. Colonoscopy training: the need for patience (patients). ANZ J Surg 2002; 72: 89-91

[14] Park HJ, Hong JH, Kim HS et al. Predictive factors affecting cecal intubation failure in colonoscopy trainees. BMC Med Educ 2013; 13: 5

[15] Ward ST, Mohammed MA, Walt R et al. An analysis of the learning curve to achieve competency at colonoscopy using the JETS database. Gut 2014; 63: 1746 - 1754

[16] Bowles C], Leicester R, Romaya C et al. A prospective study of colonoscopy practice in the UK today: are we adequately prepared for national colorectal cancer screening tomorrow? Gut 2004; 53: 277 283 